\title{
Poluição visual no setor histórico do município de Paranaguá - PR
}

Visual pollution in the historical sector of the municipality of Paranaguá $-P R$

Poluición visual en el sector histórico del municipio de Paranaguá - $P R$

Leonice Fraga Andrete

Estudante do curso de especialização em Gestão Ambiental, IFPR-Paranaguá, Brasil leonicefraga@bol.com.br

Emerson Luis Tonetti

Professor Doutor, IFPR-Paranaguá, Brasil. emerson.tonetti@ifpr.edu.br 


\section{RESUMO}

O presente trabalho se refere a uma pesquisa sobre poluição visual, realizada no setor histórico do Município de Paranaguá, litoral do Estado do Paraná. A pesquisa iniciou-se com as leituras do Plano Diretor de Desenvolvimento Integrado de Paranaguá, com foco na Lei Complementar no 62/2007, que institui o zoneamento do uso e ocupação do solo do município. Deste documento foram selecionadas as normativas relacionadas com a publicidade ao ar livre, principalmente aquelas que especificavam os padrões para a publicidade ao ar livre. $O$ objetivo geral foi investigar se a publicidade ao ar livre constituia poluição visual no setor histórico do Município de Paranaguá, no litoral do Paraná. Especificamente verificar se as áreas ocupadas estavam em desacordo com a normatização estabelecida no Plano Diretor do município. Três segmentos de ruas, representativos do setor histórico, foram selecionados para a coleta de dados, em planilhas previamente elaboradas. No total, 268 imóveis foram investigados. Desse total, $77 \%$ apresentavam publicidade na fachada. Destes, 47,69\% dos imóveis não estavam de acordo com a regra de $1 / 3$ da fachada, $42,06 \%$ encontravam-se com publicidade acima do segundo piso, $63,15 \%$ dos imóveis apresentavam irregularidades com a presença de letreiro perpendicular e apenas $9 \%$ possuíam publicidade obstruindo portas e janelas, acima das edificações e com vedação nas fachadas. Esses resultados podem incentivar políticas públicas que priorizem a diminuição dos inúmeros tipos de poluição visual na cidade e promover a melhoria na qualidade do ambiente urbano para a população.

PALAVRAS-CHAVE: Paranaguá. Poluição visual. Publicidade ao ar livre.

\section{ABSTRACT}

The present paper refers to a research on visual pollution, carried out in the historical sector of the Municipality of Paranaguá, Paraná State. The research began with the readings of the Integrated Development Master Plan of Paranaguá, focusing on Complementary Law 62/2007, which establishes the zoning of land use and occupation of the municipality. From this document we selected the regulations related to outdoor advertising, especially those that specified the standards for outdoor advertising. The general objective was to investigate whether outdoor advertising constituted visual pollution in the historical sector of the Municipality of Paranaguá, on the coast of Paraná. More specifically, to verify if the occupied areas were in disagreement with the normalization established in the Master Plan of the municipality. Three segments of streets, representatives of the historical sector, were selected for data collection, on previously elaborated worksheets. In total, 268 properties were investigated. Of this total, $77 \%$ had advertising on the front. Of these, $47.69 \%$ of the properties were not in accordance with the rule of $1 / 3$ of the facade, $42.06 \%$ were with publicity above the second floor, $63.15 \%$ of the buildings presented irregularities with the presence of perpendicular signs, and only $9 \%$ had advertising, obstructing doors and windows, above the buildings and with blockage of the facades. These results can encourage public policies that prioritize the reduction of the many types of visual pollution in the city and promote the improvement in the quality of the urban environment for the population.

KEYWORDS: Paranaguá. Visual pollution. Outdoor advertising.

\section{RESUMEN}

El presente trabajo se refiere a una investigación sobre contaminación visual, realizada en el sector histórico del Municipio de Paranaguá, litoral del Estado de Paraná. La investigación se inició con las lecturas del Plan Director de Desarrollo Integrado de Paranaguá, con foco en la Ley Complementaria no 62/2007, que instituye la zonificación del uso y ocupación del suelo del municipio. De este documento se seleccionaron las normativas relacionadas con la publicidad al aire libre, principalmente aquellas que especificaban los estándares para la publicidad al aire libre. El objetivo general fue investigar si la publicidad al aire libre constituía contaminación visual en el sector histórico del Municipio de Paranaguá, en el litoral del Paraná. Específicamente verificar si las áreas ocupadas estaban en desacuerdo con la normatización establecida en el Plan Director del municipio. Tres segmentos de calles, representativos del sector histórico, fueron seleccionados para la recolección de datos, en planillas previamente elaboradas. En total, 268 inmuebles fueron investigados. De ese total, el 77\% presentaba publicidad en la fachada. El 47,69\% de los inmuebles no estaban de acuerdo con la regla de $1 / 3$ de la fachada, el $42,06 \%$ se encontraban con publicidad por encima del segundo piso, el $63,15 \%$ de los inmuebles presentaban irregularidades con la presencia de letrero perpendicular $\mathrm{Y}$ sólo el $9 \%$ tenía publicidad obstruyendo puertas y ventanas, por encima de las edificaciones y con sellado en las fachadas. Estos resultados pueden incentivar políticas públicas que prioricen la disminución de los numerosos tipos de contaminación visual en la ciudad y promover la mejora en la calidad del ambiente urbano para la población.

PALABRAS CLAVE: Paranaguá. Contaminación visual. Publicidad al aire libre. 


\section{INTRODUÇÃO}

A poluição visual é um problema de grandes proporções nos centros urbanos, e causa vários agravos à harmonia urbana e à qualidade de vida da população.

Os elementos que promovem a poluição visual, quando dispostos em grande quantidade, podem gerar uma sensação de mal-estar para a população urbana, pois a cidade assume um espaço apenas de relações comerciais, escondendo a sua arquitetura original, geram cansaço visual, além de causar transtornos no trânsito, podendo ocasionar acidentes em razão do desvio de atenção dos motoristas e pedestres.

O município de Paranaguá, no litoral do Estado do Paraná, atua como um pólo econômico regional. Destaca-se dos demais municípios pelo número de habitantes, 140.450 habitantes (IBGE, 2010), e pela presença do Porto Dom Pedro II, ou porto de Paranaguá, como é mais conhecido. No setor histórico do município existe uma concentração de atividades comerciais e de seus respectivos meios de propaganda que interagem com os aspectos arquitetônicos históricos locais.

Nesse contexto, pretende-se investigar se a publicidade ao ar livre constitui poluição visual no setor histórico do Município de Paranaguá, no litoral do Paraná. Especificamente objetiva-se verificar se a área ocupada vinculada por meio de anúncios com placas e letreiros, afixadas em estabelecimentos comerciais e de serviços, em logradouros públicos, em locais visíveis ou expostos ao público, em mobiliário urbano ou outros equipamentos, para a indicação de referência de produtos, de serviços ou de atividades estão em desacordo com a normatização estabelecida no Plano Diretor de Paranaguá.

Pesquisas sobre poluição visual nos centros urbanos podem incentivar políticas públicas que priorizem a diminuição dos inúmeros tipos de poluição visual na cidade de Paranaguá/PR, promovendo a qualidade de vida dos cidadãos e sensibilização das empresas de publicidade para promover a melhoria na qualidade do ambiente urbano da população parnanguara.

\section{PUBLICIDADE AO AR LIVRE NO SETOR HISTÓRICO DE PARANAGUÁ}

De forma geral, o termo poluição visual é utilizado para indicar o excesso ou alterações de elementos da paisagem. Contudo, não existe correspondência entre o uso comum do termo e sua interpretação legal.

O vocábulo poluição, formado do verbo poluir, do latim polluere, significa estragar, sujar, corromper. Sendo, genericamente, tomado na mesma significação de contaminação, inutilização a qualquer coisa, em vista do que a mesma se torna imprópria ao uso ou ao fim a que se destinava, conforme descrição de De Plácido e Silva (1982).

Assim, no senso comum, a poluição visual está vinculada a maculação visual da paisagem por "impurezas" que caracterizam uso impróprio ou inadequado a que se destinava, provocando um desconforto visual.

Na prática, a poluição visual acontece em ambientes urbanos em que há concentração de lojas, edifícios comerciais, edifícios residenciais, prédios de escritórios, etc., resultando no surgimento de centros comerciais, e, em decorrência disso, na colocação descontrolada de cartazes publicitários, tais como anúncios, banners, placas, outdoors, instalados ao longo das vias urbanas e nas fachadas das edificações. Também, grafite, pichações, fios de eletricidade e 
telefônicos, lixo, entre outros elementos em desarmonia, comum nos centros comerciais, geram desconforto visual. Todos esses fatores impedem ou dificultam a percepção dos espaços urbanos dos centros comerciais da cidade, caracterizando a verdadeira poluição visual (PARANAGUÁ, 2007).

Em nosso país criaram-se várias normas legais destinadas à proteção ambiental e à vida da população. Entre elas destaca-se a Constituição da República Federativa do Brasil de 1988, a qual no Capítulo VI dedicado ao meio ambiente, em seu artigo 225 estabelece que:

Art. 225. Todos têm direito ao meio ambiente ecologicamente equilibrado, bem de uso comum do povo e essencial à sadia qualidade de vida, impondo-se ao Poder Público e à coletividade o dever de defendê-lo e preservá-lo para as presentes e futuras gerações. (BRASIL, 1988).

A Política Nacional do Meio Ambiente tem por objetivo a preservação, melhoria e recuperação da qualidade ambiental propícia à vida, visando assegurar, no país, condições ao desenvolvimento sócio-econômico, aos interesses da segurança nacional e à proteção da dignidade da vida humana. (BRASIL, 1981, Art. 2º).

Para os fins previstos nesta Lei, entende-se por:

I - meio ambiente, o conjunto de condições, leis, influências e interações de ordem física, química e biológica, que permite, abriga e rege a vida em todas as suas formas; II - degradação da qualidade ambiental, a alteração adversa das características do meio ambiente; III - poluição, a degradação da qualidade ambiental resultante de atividades que direta ou indiretamente: a) prejudiquem a saúde, a segurança e o bem-estar da população; b) criem condições adversas às atividades sociais e econômicas; c) afetem desfavoravelmente a biota; d) afetem as condições estéticas ou sanitárias do meio ambiente; e) lancem matérias ou energia em desacordo com os padrões ambientais estabelecidos. (BRASIL, 1981, Art. 3ㅇ, i I, II, III).

Segundo Pereira Junior, (2002), temos, então, de verificar se a proliferação indiscriminada de outdoors, cartazes, luminosos e outras formas de propaganda, as quais chamamos genericamente de "poluição visual" enquadram-se nas definições de poluição expressa pela Lei $6.938 / 81$, ou se trata apenas de uma forma de utilização do solo e do meio urbano. Nesse aspecto, observamos que essa proliferação: não prejudica a saúde, a segurança e o bem-estar da população; não cria condições adversas às atividades sociais e econômicas, ao contrário,podem constituir atividades econômicas; não afeta desfavoravelmente a biota, ou seja, não prejudica a flora e a fauna; não afeta as condições sanitárias do meio ambiente; não lança matérias ou energia em desacordo com os padrões ambientais estabelecidos.

Restam dúvidas apenas quanto aos prejuízos estéticos que podem ser causados ao meio ambiente. Mas esta é uma questão subjetiva e dependente de padrões culturais e dificilmente poderá ser plenamente definida em norma legal (PEREIRA JUNIOR, 2002).

Como não é possível enquadrar a poluição visual no conceito clássico e tecnicamente aceito de poluição, pode-se verificar se as atividades que a geram referem-se à utilização do solo urbano (PEREIRA JUNIOR, 2002).

Sendo assim, a poluição visual é formada basicamente pela colocação de cartazes ou outdoors e/ou por anúncios luminosos ao longo das vias urbanas e nas fachadas dos edifícios. Pode-se considerar também como poluição visual as ocupações irregulares de terrenos públicos, geralmente situadas em margens de avenidas e em encostas não adequadas à urbanização. Todas essas causas de degradação da paisagem urbana ligam-se a alguma forma de ocupação do solo urbano. 
Desta forma, compete ao Município, "promover, no que couber, adequado ordenamento territorial, mediante planejamento e controle do uso, do parcelamento e da ocupação do solo urbano" (BRASIL, 1988 art. 30, i VIII apud PEREIRA JUNIOR, 2002). Assim, a poluição visual das áreas urbanas ocorre, portanto, ou com o consentimento do poder público municipal, ou pela ineficiência ou negligencia dele (PEREIRA JUNIOR, 2002).

Sendo assim, só o Município tem condições operacionais e competência de legislar e de fiscalizar a ocupação do solo urbano. Comenta o autor:

Concluindo, parece-nos claro que compete exclusivamente ao Município legislar sobre a colocação de placas, "outdoors", letreiros luminosos e sobre a ocupação do solo urbano em geral, não podendo a União legislar sobre esses temas além das normas gerais por ela já implantadas, as quais tratam da proteção ao meio ambiente de uma forma ampla. (PEREIRA JUNIOR, 2002, p. 5).

Por essas razões, poluição visual não é caracterizada como crime ambiental e cabe à Prefeitura de Paranaguá o papel de fiscalizar esta problemática, uma vez que, para instalação de qualquer forma de publicidade é necessária a obtenção da anuência municipal de uso e ocupação do solo. Este documento para ser adquirido, primeiramente é analisado pela câmara técnica multidisciplinar e posteriormente deve ser aprovado pelo Conselho Municipal de Obras e Urbanismo e Meio Ambiente (PEREIRA JUNIOR, 2002).

Esta fiscalização tem que ser cobrada por parte da população que se sentir prejudicada e cabe ao poder público tomar as devidas precauções e atitudes para conservação do meio ambiente municipal.

No presente trabalho é importante assinalar que a competência legal para legislar sobre a presente matéria é dos municípios. Assim, em conformidade com o que determina o inciso VIII, art. 30, da Constituição Federal de 1988, cabe ao município promover, legislar e fiscalizar o uso e a instalação de publicidade ao ar livre em seu território.

Adotando essa determinação constitucional, o Município de Paranaguá, Paraná, sancionou a Lei Complementar $n^{\circ}$ 62, de 27 de agosto de 2007, que dispõe sobre a divisão do território do Município de Paranaguá em zonas e setores e estabelece critérios e parâmetros de uso e ocupação do solo, com o objetivo de orientar e ordenar o crescimento da cidade (PARANAGUÁ, 2007).

Nesse sentido, para o presente estudo da poluição visual, destacamos o Art. 92 e seus incisos da referida Lei Complementar, que trata sobre a instalação de publicidade ao ar livre no Setor Histórico de Paranaguá, cuja determinação a seguir se transcreve:

Art. 92 Quanto à instalação de Publicidade ao Ar Livre no Setor Histórico define-se que:

I. a publicidade ao ar livre, veiculada por meio de anúncios com placas e letreiros, afixada em estabelecimentos comerciais e de serviços, em logradouros públicos, em locais visíveis ou expostos ao público, em mobiliário urbano ou outros equipamentos, para a indicação de referência de produtos, de serviços ou de atividades, deverá se harmonizar, pelas suas dimensões, escala, proporções e cromatismo, com as características do Setor, compatibilizando-se com a paisagem urbana e garantindo a integridade arquitetônica de suas edificações;

II. a área para letreiro, anúncio ou placa não poderá ser superior à terça parte do comprimento de fachada do próprio estabelecimento multiplicada por $1 \mathrm{~m}$ (um metro);

III. no caso de mais de um estabelecimento em uma mesma edificação, a área destinada à publicidade deverá ser subdividida proporcionalmente entre todos;

IV. qualquer inscrição direta nos toldos será levada em consideração para efeito de cálculo da área de publicidade; 
V. será permitida a subdivisão de letreiro desde que a soma das áreas não ultrapasse a área total permitida;

VI. a localização da publicidade nas edificações não poderá ultrapassar o nível do piso do $2^{\circ}$ pavimento;

VII. as placas e letreiros perpendiculares à fachada não poderá ultrapassar $60 \mathrm{~cm}$ (sessenta centímetros) de balanço, deverão ter como limite superior a verga dos vãos e permitir uma altura livre de $2,50 \mathrm{~m}$ (dois metros e cinquenta centímetros), observada a distância mínima de $50 \mathrm{~cm}$ (cinquenta centímetros) do meio fio; VIII. será vedada a publicidade que afete a perspectiva ou deprecie, de qualquer modo, o aspecto do edifício ou paisagem, vias e logradouros públicos, bem como em calçadas, em árvores, postes e monumentos;

IX. não será permitida a colocação de publicidade que obstrua porta, janela ou qualquer abertura destina à iluminação ou ventilação;

X. não será permitida e publicidade colocada no alto de edifícios e nem colocada ou pintada diretamente em muros ou paredes frontais ao passeio ou às vias e logradouros públicos;

XI. não será permitida a utilização de qualquer elemento de vedação de fachada; (PARANAGUÁ, 2007, art. 92, i I- XI).

No mesmo artigo da lei complementar, em parágrafo único temos "A critério da Prefeitura Municipal de Paranaguá e com a aprovação da Coordenaria do Patrimônio Cultural, poderá ser admitida publicidade no mobiliário urbano e equipamento social urbano e a execução de painéis artísticos em muros e paredes." (PARANAGUÁ, 2007, Art. 92).

Contudo, a questão da poluição visual não se resume na existência da propaganda em si, mas o seu descontrole na colocação do material publicitário.

A poluição visual, além de promover o desconforto espacial e visual daqueles que transitam por estes locais, acaba por tirar a beleza das cidades, desvalorizando-as e tornando-as apenas um espaço de promoção das vendas. Assim, o problema, não é a existência da propaganda, mas o seu descontrole.

Tomando os referidos artigos da legislação municipal, citados acima, foram elaborados os critérios e os procedimentos para coleta de dados que são descritos a seguir.

\section{METODOLOGIA}

O procedimento para a realização do presente trabalho de pesquisa iniciou com as leituras do Plano Diretor de Desenvolvimento Integrado de Paranaguá (PDDIP), com foco na Lei Complementar $n$ ㅇ 62/2007, que institui o zoneamento do uso e ocupação do solo do município (PARANAGUÁ, 2007).

Do referido documento foram selecionadas as normativas relacionadas com a publicidade ao ar livre, principalmente aquelas que especificavam os padrões para a publicidade ao ar livre no setor histórico de Paranaguá, ou seja, artigo 92, do inciso I ao XI (PARANAGUÁ, 2007), esquematicamente apresentados no quadro 1. 


\section{Periódica Eletronica \\ Fórum Ambiental}

da Alta Paulista

Quadro 1 - Representação esquemática da interpretação dos incisos do art. 92 da LC 62/2007

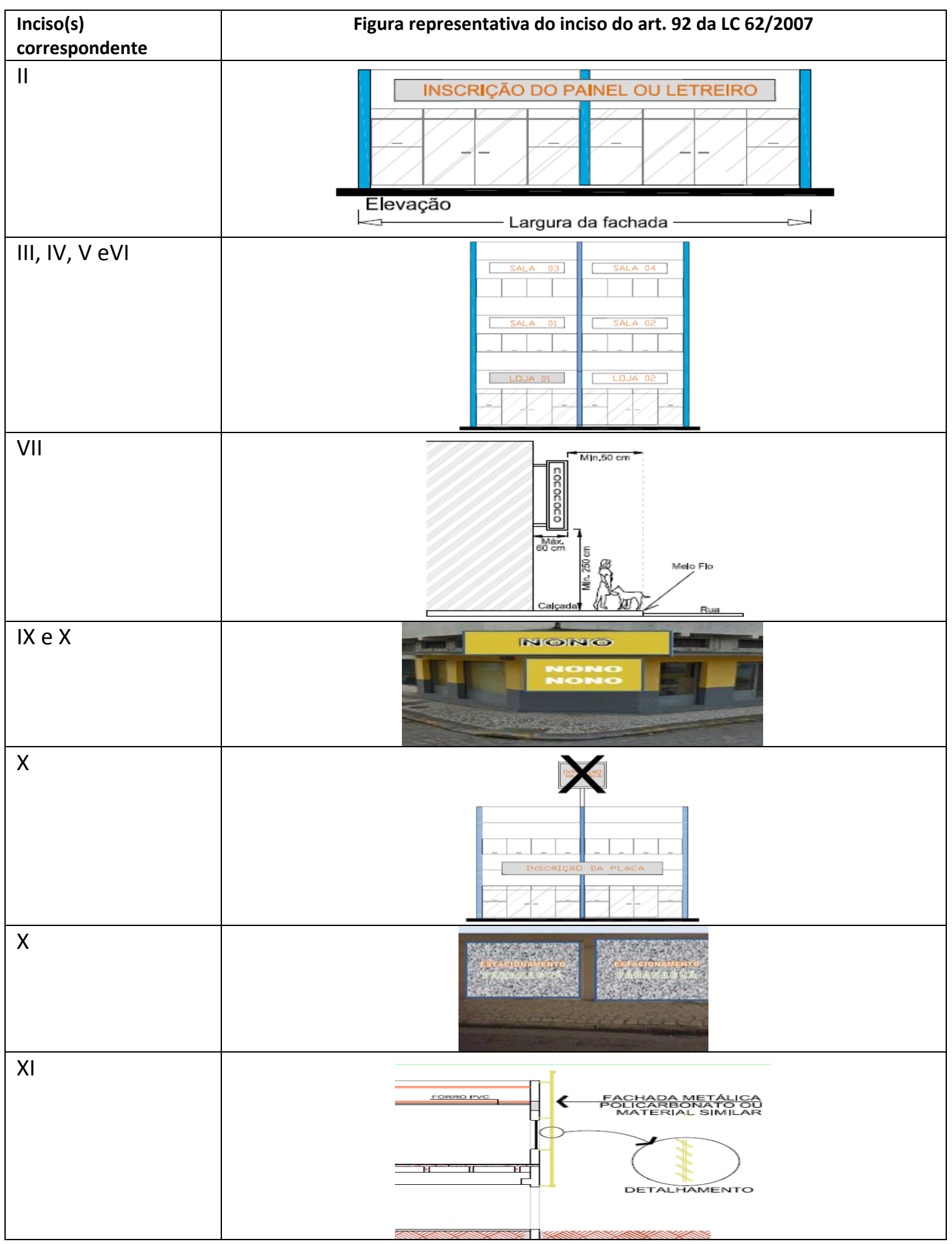

Fonte: prefeitura municipal de Paranaguá.

A partir dessas normativas criou-se a planilha de coleta de dados, apresentada nas tabelas $1 \mathrm{e}$ 2. 
Tabela 1 - Ferramenta para coleta de dados sobre publicidade ao ar livre no setor histórico de Paranaguá.

\begin{tabular}{|l|l|l|}
\hline \multicolumn{2}{|c|}{ INFORMAÇÕES DOS IMÓVEIS DE PARANAGUÁ/PR } & No do Imóvel: \\
\hline Rua: & & \\
\hline Fachada, no do imóvel. & & \\
\hline Tem Publicidade na Fachada? & & \\
\hline Regra art. 92/II a V (1/3). De acordo? & & \\
\hline Tem Segundo Pavimento? & & \\
\hline $\begin{array}{l}\text { Tem Publicidade Acima do Piso do 2o Pavimento? (Regra Art. } \\
\text { 92/VI) }\end{array}$ & & \\
\hline Tem Letreiro Perpendicular? & & \\
\hline Está de acordo com a Regra art.92/VII? & & \\
\hline $\begin{array}{l}\text { Tem publicidade Obstruindo Porta, Janela, ou Abertura para } \\
\text { Luz/Ventilação? Art92/IX }\end{array}$ & & \\
\hline Tem Publicidade Acima da Edificação? Art92/x & & \\
\hline Tem Elemento de Vedação de Fachada? (art.92/XI) & & \\
\hline Obs. 1 - O “X” representa descumprimento da regra. & & \\
\hline
\end{tabular}

Fonte: os autores.

Tabela 2 - Ferramenta para calcular a porcentagem de imóveis em desacordo com as normativas do Plano Diretor Municipal.

\begin{tabular}{|l|l|l|}
\hline PARÂMETROS DA PUBLICIDADE AO AR LIVRE & & \\
\hline Presença de Publicidade na Fachada & & \\
\hline De acordo com a regra de 1\3 da fachada & & \\
\hline Presença de Segundo Pavimento & & \\
\hline Presença de Publicidade Acima do Segundo Piso & & \\
\hline Presença de Letreiro Perpendicular & & \\
\hline De acordo com a regra do letreiro perpendicular & & \\
\hline Tem Publicidade Obstruindo Portas e Janelas & & \\
\hline Tem Publicidade acima da Edificação & & \\
\hline Tem Elementos de Vedação da Fachada & № \\
\hline TOTAL: & & \\
\hline
\end{tabular}

Fonte: os autores.

Os dados dos respectivos quadros foram inseridos no "software" Excel para realização dos cálculos necessários.

No setor histórico da cidade de Paranaguá se localizam o centro comercial do município, onde existem várias ruas com edifícios, casas, lojas e outros estabelecimentos comerciais. Dentre todo o setor histórico, as ruas Faria Sobrinho, XV de Novembro e Marechal Deodoro, são as mais representativas, e é onde se observa um grande acúmulo de publicidade ao ar livre, motivo pelo qual as referidas vias foram escolhidas para a coletas de dados, para representar as informações sobre a "poluição visual" decorrente da publicidade ao ar livre no setor histórico do município. 
A coleta de dados iniciou na rua Faria Sobrinho esquina com a rua João Regis e terminou na esquina da rua Manoel Bonifácio. Na rua XV de Novembro iniciou na rua Prisciliano Corrêa e findou na rua Professor Cleto.Na rua Marechal Deodoro o início deu-se no Largo Cônego Alcindino e o término na rua Professor Cleto.

Foram consideradas apenas as fachadas dos imóveis das referidas ruas, sendo que todos foram avaliados, independentemente de seu uso. De posse dos dados coletados nas citadas ruas, foram gerados os gráficos para apresentar as informações sobre a "poluição visual" decorrente da publicidade ao ar livre no setor histórico do município.

\section{ANÁLISE E DISCUSSÃO DOS RESULTADOS}

Após a coleta de dados, das referidas ruas do setor histórico de Paranaguá, duzentos e sessenta e oito (268) imóveis foram investigados quanto à observância ou não das normativas referentes à publicidade ao ar livre (Tabela 3), presente na Lei Complementar 62/2007 do Plano Diretor de Desenvolvimento Integrado de Paranaguá (PARANAGUÁ, 2007). Desse total de imóveis, verificou-se que $77 \%$ deles apresentavam publicidade na fachada como mostra a tabela abaixo, onde $47,69 \%$ dos imóveis não estão de acordo com a regra de $1 / 3$ da fachada (Figura 1), 42,06\% encontram-se com publicidade acima do segundo piso (Figura 2), 63,15\% dos imóveis apresentam irregularidades com regra do letreiro perpendicular (Figura 3) e somando os restantes dos dados apenas $9 \%$ possuem publicidade obstruindo portas e janelas, acima das edificações e com vedação nas fachadas (Figura 1 e 4). 


\section{Periódica Eletrâmica \\ Fórum Ambiental}

da Alta Paulista

Tabela 3 - Resultado da coleta dos parâmetros legais da publicidade ao ar livre em relação ao total de imóveis verificados das ruas avaliadas.

\begin{tabular}{|c|c|c|c|c|c|}
\hline \multirow{2}{*}{$\begin{array}{l}\text { PARAMETROS DA PUBLICIDADE } \\
\text { AO AR LIVRE }\end{array}$} & \multicolumn{2}{|c|}{ SIM } & \multicolumn{2}{|c|}{ NÃO } & \multirow[t]{2}{*}{ TOTAL } \\
\hline & № & $\%$ & № & $\%$ & \\
\hline Publicidade na Fachada & 195 & $77,00 \%$ & 73 & 27,23 & 268 \\
\hline $\begin{array}{l}\text { De acordo com a Regra de } 1 / 3 \\
\text { da fachada }\end{array}$ & 102 & 52,30 & 93 & 47,69 & 195 \\
\hline $\begin{array}{l}\text { Presença de Segundo } \\
\text { Pavimento }\end{array}$ & 145 & 54,10 & 123 & 45,89 & 268 \\
\hline $\begin{array}{l}\text { Presença de publicidade acima } \\
\text { do Segundo Piso }\end{array}$ & 61 & 42,06 & 84 & 57,46 & 145 \\
\hline $\begin{array}{l}\text { Presença de Letreiro } \\
\text { Perpendicular }\end{array}$ & 114 & 42,53 & 154 & 57,46 & 268 \\
\hline $\begin{array}{l}\text { De acordo com a Regra do } \\
\text { Letreiro Perpendicular }\end{array}$ & 42 & 36,84 & 72 & 63,15 & 114 \\
\hline $\begin{array}{l}\text { Tem Publicidade Obstruindo } \\
\text { Portas e Janelas }\end{array}$ & 24 & 8,95 & 244 & 91,04 & 268 \\
\hline $\begin{array}{l}\text { Tem Publicidade Acima da } \\
\text { Edificação }\end{array}$ & 2 & 0,74 & 266 & 99,25 & 268 \\
\hline $\begin{array}{l}\text { Elementos de Vedação da } \\
\text { Fachada }\end{array}$ & 0 & 0 & 268 & 100 & 268 \\
\hline
\end{tabular}

Fonte: os autores.

Figura 1 - representação das irregularidades correspondentes aos incisos II, IX e X da Lei Complementar 62/2007 do Plano Diretor de Paranaguá.

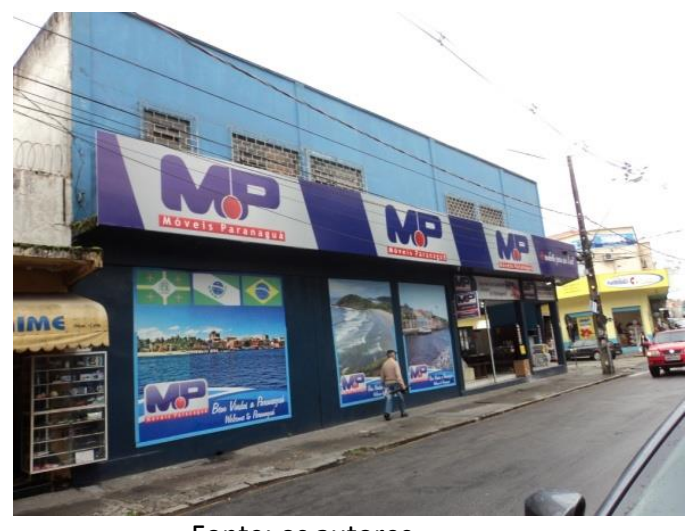

Fonte: os autores. 


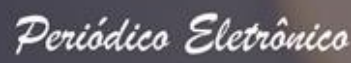 \\ Fórum Ambiental}

Figura 2 - representação das irregularidades correspondentes ao inciso IV da Lei Complementar 62/2007 do Plano Diretor de Paranaguá.

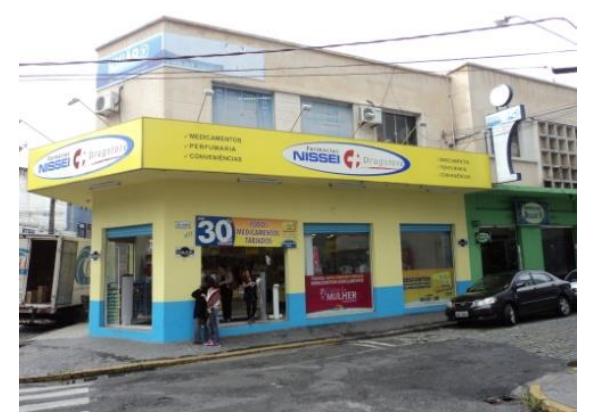

Fonte: os autores.

Figura 3 - representação das irregularidades correspondentes ao inciso VII da Lei Complementar 62/2007 do Plano Diretor de Paranaguá.

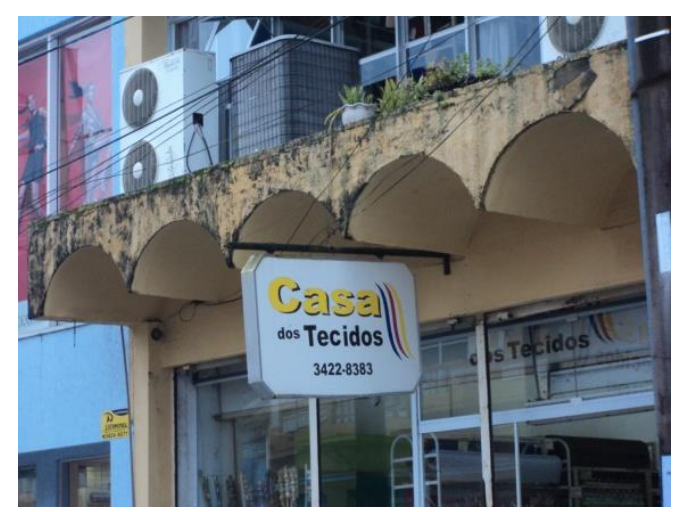

Fonte: os autores.

Figura 4 - representação das irregularidades correspondentes ao inciso VII da Lei Complementar 62/2007 do Plano Diretor de Paranaguá.

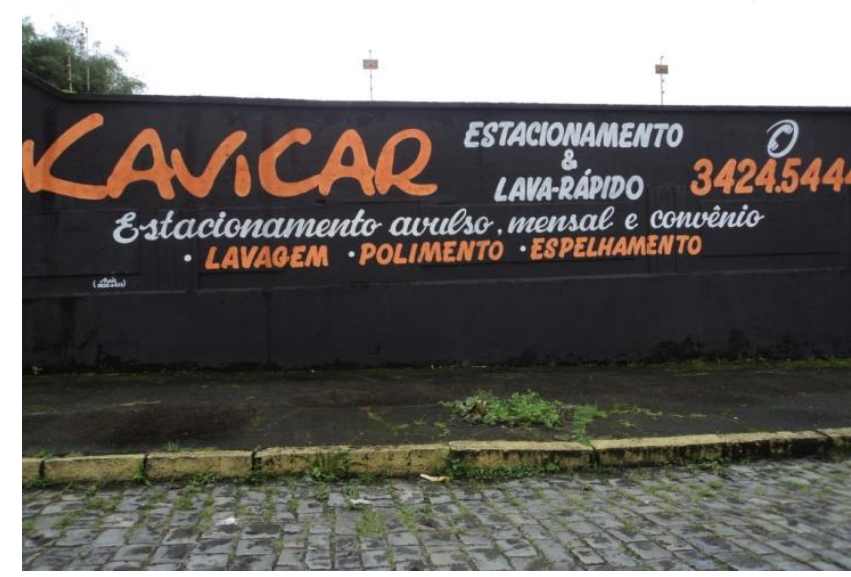

Fonte: os autores.

Com o surgimento destes dados citados acima, foi necessário separar as coletas por ruas para um melhor entendimento e percepção quanto à dificuldade das coletas dos dados em relação 
ao tempo e a ajuda de terceiros, uma vez que as coletas tinham datas específicas para acontecer. Nesse sentido, a descrição dos resultados obtidos nas ruas Faria Sobrinho, XV de Novembro e Marechal Deodoro, são apresentados nas tabelas 4, 5 e 6 respectivamente.

Tabela 4 - Resultado da coleta dos parâmetros legais da publicidade ao ar livre em imóveis em desacordo com as normativas do Plano Diretor na rua Faria Sobrinho.

\begin{tabular}{|c|c|c|c|c|c|}
\hline \multirow{2}{*}{$\begin{array}{l}\text { PARAMETROS DA PUBLICIDADE AO AR } \\
\text { LIVRE }\end{array}$} & \multicolumn{2}{|c|}{ SIM } & \multicolumn{2}{|c|}{ NÃO } & \multirow[t]{2}{*}{ TOTAL } \\
\hline & № & $\%$ & № & $\%$ & \\
\hline Presença de publicidade na fachada & 93 & 75,00 & 31 & 25,00 & 124 \\
\hline $\begin{array}{l}\text { De acordo com a regra de } 1 / 3 \text { da } \\
\text { fachada }\end{array}$ & 59 & 63,44 & 34 & 36,55 & 93 \\
\hline Presença de segundo pavimento & 77 & 62,09 & 47 & 37,90 & 124 \\
\hline $\begin{array}{l}\text { Presença de publicidade acima do } \\
\text { segundo piso }\end{array}$ & 22 & 28,57 & 55 & 71,42 & 77 \\
\hline Presença de letreiro perpendicular & 54 & 43,54 & 70 & 56,45 & 124 \\
\hline $\begin{array}{l}\text { De acordo com a regra do letreiro } \\
\text { perpendicular }\end{array}$ & 16 & 29,62 & 38 & 70,37 & 54 \\
\hline $\begin{array}{l}\text { Tem publicidade obstruindo portas e } \\
\text { janelas }\end{array}$ & 15 & 12,09 & 109 & 87,90 & 124 \\
\hline Tem publicidade acima da edificação & 1 & 0,80 & 123 & 90,19 & 124 \\
\hline $\begin{array}{l}\text { Tem elementos de vedação da } \\
\text { fachada }\end{array}$ & 0 & 0 & 124 & 100,00 & 124 \\
\hline
\end{tabular}

Fonte: os autores

Os resultados apresentados acima mostram que as coletas realizadas na rua Faria Sobrinho apresentam uma porcentagem de $36,55 \%$ de imóveis que estão irregulares quanto a regra de $1 / 3$ da fachada, $28,57 \%$ apresentam publicidade acima do segundo piso, $70,37 \%$ irregulares quanto a regra de letreiro perpendicular e ainda, 12,89\% dos imóveis apresentam irregularidades obstruindo portas e janelas, publicidade acima da edificação e vedação da fachada. 


\section{Periódica Eletrônica \\ Fórum Ambiental}

da Alta Paulista

Tabela 5 - Resultado da coleta dos parâmetros legais da publicidade ao ar livre em imóveis em desacordo com as normativas do Plano Diretor na rua XV de Novembro.

\begin{tabular}{|c|c|c|c|c|c|}
\hline \multirow{2}{*}{$\begin{array}{l}\text { PARAMETROS DA PUBLICIDADE AO AR } \\
\text { LIVRE }\end{array}$} & \multicolumn{2}{|c|}{ SIM } & \multicolumn{2}{|c|}{ NÃO } & \multirow[t]{2}{*}{ TOTAL } \\
\hline & № & $\%$ & № & $\%$ & \\
\hline Presença de publicidade na fachada & 39 & 60,93 & 25 & 39,06 & 64 \\
\hline De acordo com a regra de $1 / 3$ da fachada & 19 & 48,71 & 20 & 51,28 & 39 \\
\hline Presença de segundo pavimento & 31 & 48,43 & 33 & 51,56 & 64 \\
\hline $\begin{array}{l}\text { Presença de publicidade acima do } \\
\text { segundo piso }\end{array}$ & 18 & 58,06 & 13 & 41,93 & 31 \\
\hline Presença de letreiro perpendicular & 22 & 34,37 & 42 & 65,62 & 64 \\
\hline $\begin{array}{l}\text { De acordo com a regra do letreiro } \\
\text { perpendicular }\end{array}$ & 4 & 18,18 & 18 & 81,81 & 22 \\
\hline $\begin{array}{l}\text { Tem publicidade obstruindo portas e } \\
\text { janelas }\end{array}$ & 4 & 6,25 & 60 & 93,75 & 64 \\
\hline Tem publicidade acima da edificação & 0 & 0 & 64 & 100 & 64 \\
\hline Tem elementos de vedação da fachada & 0 & 0 & 64 & 100 & 64 \\
\hline
\end{tabular}

Fonte: os autores.

Mais uma vez os resultados obtidos mostram uma grande porcentagem de irregularidades quanto à "poluição visual", desta vez na rua XV de Novembro.

Podemos observar que $51,28 \%$ dos imóveis apresentaram-se fora dos padrões da regra de $1 / 3$ da fachada, 58,06\% dos imóveis apresentam fachadas acima do segundo piso, $81,81 \%$ desobedecem à regra do letreiro perpendicular e apenas 6,25\% dos imóveis tem publicidade obstruindo portas e janelas. 
Tabela 6 - Resultado da coleta dos parâmetros legais da publicidade ao ar livre em imóveis em desacordo com as normativas do Plano Diretor na rua Marechal Deodoro.

\begin{tabular}{|c|c|c|c|c|c|}
\hline \multirow{2}{*}{$\begin{array}{l}\text { PARAMETROS DA PUBLICIDADE AO AR } \\
\text { LIVRE }\end{array}$} & \multicolumn{2}{|c|}{ SIM } & \multicolumn{2}{|c|}{ NÃO } & \multirow[t]{2}{*}{ TOTAL } \\
\hline & № & $\%$ & № & $\%$ & \\
\hline Presença de publicidade na fachada & 63 & 78,75 & 17 & 21,25 & 80 \\
\hline $\begin{array}{l}\text { De acordo com a regra de } 1 \backslash 3 \mathrm{da} \\
\text { fachada }\end{array}$ & 24 & 38,09 & 39 & 61,90 & 63 \\
\hline Presença de segundo pavimento & 37 & 46,25 & 43 & 53,75 & 80 \\
\hline $\begin{array}{l}\text { Presença de publicidade acima do } \\
\text { segundo piso }\end{array}$ & 21 & 56,75 & 16 & 43,24 & 37 \\
\hline Presença de letreiro perpendicular & 38 & 47,5 & 42 & 52,5 & 80 \\
\hline $\begin{array}{l}\text { De acordo com a regra do letreiro } \\
\text { perpendicular }\end{array}$ & 22 & 57,89 & 16 & 42,10 & 38 \\
\hline $\begin{array}{l}\text { Tem publicidade obstruindo portas e } \\
\text { janelas }\end{array}$ & 5 & 6,25 & 75 & 93,75 & 80 \\
\hline Tem publicidade acima da edificação & 1 & 1,25 & 79 & 98,75 & 80 \\
\hline $\begin{array}{l}\text { Tem elementos de vedação da } \\
\text { fachada }\end{array}$ & 0 & 0 & 80 & 100 & 80 \\
\hline
\end{tabular}

Fonte: os autores

E por fim os resultados obtidos na rua Marechal Deodoro também mostram grande porcentagem de irregularidades, porquanto $61,90 \%$ dos imóveis apresentam-se fora dos padrões da regra de $1 / 3$ da fachada, $42,10 \%$ dos imóveis apresentam fachadas acima do segundo piso, $81,81 \%$ desobedecem à regra do letreiro perpendicular e apenas $7,50 \%$ dos imóveis tem publicidade obstruindo portas e janelas.

Como já mencionado acima, estes resultados só mostram um pouco da problemática da poluição visual de Paranaguá/PR.

As informações obtidas representam uma amostra da real condição da poluição visual no município e que deve ser considerada em novos estudos e pode ser inserida na gestão pública, por ocasião da revisão do Plano Diretor.

\section{CONSIDERAÇÕES FINAIS}

Pode-se observar durante a pesquisa que a maioria das instalações comercias visitadas do setor histórico de Paranaguá/PR, encontravam-se irregulares quanto às normas referentes ao plano diretor municipal.

Ao verificar especificamente se a área amostrada possui meios de anúncios de propaganda ou comunicação em suas edificações constatou-se alto índice de presença de publicidade. Destes imóveis, as irregularidades relacionadas com a regra da utilização acima de $1 / 3$ da fachada e com a presença de publicidade acima do segundo piso são muito significativas pelo volume e pelo posicionamento, respectivamente. Igualmente significativo é o percentual pertinente com a irregularidade relacionada com a presença dos letreiros perpendiculares. Um ponto positivo no cumprimento das normas foi o resultado encontrado com o item obstrução de portas e janelas e com a vedação nas fachadas. Poucos imóveis foram constatados em desacordo com a normativa.

No contexto do presente trabalho de pesquisa, a investigação da publicidade ao ar livre, no setor histórico do Município de Paranaguá, no litoral do Paraná, constitui poluição visual, por 
meio de anúncios com placas e letreiros, afixadas em estabelecimentos comerciais e de serviços, em logradouros públicos, em locais visíveis ou expostos ao público, em mobiliário urbano ou outros equipamentos, para a indicação de referência de produtos, de serviços ou de atividades, pois, estão em desacordo com a normatização estabelecida no Plano Diretor de Paranaguá.

Os resultados obtidos abrem precedentes para alertar os órgãos competentes sobre a necessidade da fiscalização e também a falta de informação por parte dos comerciantes. Isto é mais importante em locais cujas edificações apresentam características da história de Paranaguá em sua arquitetura. Lembrando que no local incidem as normativas municipal e federal de tombamento do patrimônio histórico.

Portanto, futuros trabalhos de pesquisa no setor histórico de Paranaguá devem considerar o levantamento dos imóveis de valor histórico que se encontram com fachada em processo de deterioração para uma eminente recuperação, além de se incentivar políticas públicas que priorizem a diminuição dos inúmeros tipos de poluição visual na cidade de Paranaguá/PR, promovendo a qualidade do ambiente para os cidadãos, a conscientização e sensibilização das empresas que utilizam e que produzem publicidade ao ar livre.

\section{REFERÊNCIAS BIBLIOGRÁFICAS}

BRASIL. Lei 6.938, de 31 de agosto de 1981. Dispõe sobre a Política Nacional do Meio Ambiente, seus fins e mecanismos de formulação e aplicação, e dá outras providências. Disponível em:<www.planalto.gov.brccivilleisL6938.htm>: Acesso em: 10 maio de 2015.

BRASIL. Constituição da República Federativa do Brasil. Distrito Federal, 1988. Disponível em: <http://www.planalto.gov.br/ccivil 03/constituicao/constitui\%C3\%A7ao.htm>: Acesso em: 15 julho 2015.

De PLÁCIDO e SILVA, Vocabulário Jurídico. Vol. III, 7. ed. Editora Forense, Rio de Janeiro: Forense, 1982.

IBGE. Instituto Brasileiro de Geografia e Estatística. Cidades, Paranaguá, 2010. Disponível em:

http://www.ibge.gov.br/cidadesat/painel/painel.php?codmun=411820. Acesso em: 12 fevereiro 2012.

PARANAGUÁ. Lei Complementar no 062, de 23 de agosto de 2007. Institui o zoneamento de uso e ocupação do solo do Município de Paranaguá e dá outras providências. Disponível em: $<$ http://www.helts.com.br/paranagua/plano diretor.php $>$ : Acesso em: 11 dezembro de 2015.

PEREIRA JÚNIOR, J. S - Legislação Federal sobre "Poluição Visual" urbana de 2002. Biblioteca Digital da Câmara de Deputados. Disponível em: <http://bd.camara.gov.br>: Acesso em: 18 agosto 2015. 